\title{
RESIDUAL LUNG VOLUME IN MITRAL DISEASE
}

\author{
BY
}

\author{
R. GARBAGNI, P. F. ANGELINO, A. BRUSCA, AND E. MINETTO \\ From Instituto di Patologia Speciale Medica e Metodologia Clinica dell'Università di Torino. Direttore: Prof. G. C. \\ Dogliotti \\ Received January 6, 1958
}

The degree of lung distension during quiet respiration, the so-called respiratory position or resting expiratory level, is essentially determined by a balance between the passive forces produced by the thoracic wall and the active forces due to the elastic properties of the lung. Therefore the interplay of these forces has a direct role in determining the extent of the functional residual capacity and, consequently, of the residual lung volume.

Previous work (Heyer et al., 1948; and Mack et al., 1947) has demonstrated that pulmonary vascular congestion does induce a certain degree of lung stiffness, and in addition pulmonary congestion is a constant finding in mitral valve disease. In view of the relationships between functional residual capacity on the one hand, and lung stiffness and pulmonary congestion on the other, this investigation was carried out with the purpose of studying the functional residual capacity in a large series of patients with pulmonary engorgement due to mitral disease.

\section{MATERIAL AND Methods}

This study was carried out in 60 patients, classified as follows. Group 1 consisted of 32 patients with tight pure mitral stenosis and usually severe dyspnœea on effort, but without any evidence of congestive heart failure at rest; 17 of these patients were women and 15 men. Their ages ranged from 21 to 49 years (mean age $=35.5$ years).

Group 2 consisted of 18 subjects with pure tight mitral stenosis and signs of congestive heart failure at rest; in this group there were 12 women and 6 men. The age of these patients varied between 22 and 49 years, with a mean age of $35 \cdot 3$ years.

Group 3 consisted of 10 patients with predominant mitral regurgitation. Functional capacity was good in two, while in the remaining eight severe dyspnœa was present at rest and/or on mild effort. Seven patients of this group were women and three were men; their age varied between 16 and 47 years (mean age $=32$ years).

The clinical diagnosis was confirmed by digital exploration of the mitral valve during valvotomy or surgical repair of valvular insufficiency.

Functional residual capacity (F.R.C.) was determined with the closed circuit method according to van Veen et al. (1952): helium was used, as proposed by Briscoe (1952), Pillot (1955) and others. By this technique it is possible to measure the intrapulmonary time of mixing, an index of the uniformity and efficiency of the intrapulmonary ventilation.

The expiratory reserve volume determined at the end of the test was subtracted from the observed F.R.C.; the difference between the two represented the residual volume (R.V.).

The lung volumes were corrected to body temperature, ambient pressure, and saturation (B.T.P.S.).

In normal subjects, both men and women, residual volume, as a percentage of total lung capacity (T.L.C.), varies according to the age of the subject as follows (Baldwin et al., 1948):

R.V./T.L.C. $=20 \%$ between the age of 16 and 34 years.

R.V./T.L.C. $=23.4^{\circ} \%$ between the age of 35 and 49 years.

R.V./T.L.C. $=30.8 \%$ between the age of 50 and 69 years.

As an index of residual volume we used this ratio between residual volume (R.V.) and the observed total lung capacity (T.L.C.). Values of this ratio higher than 30 per cent are considered to be abnormal (Gordon, 1957). 
If the theoretical value of vital capacity is known for a given patient, the theoretical absolute values of R.V. and T.L.C. can be calculated from the ratio R.V./T.L.C. However, because of the great approximation $( \pm 20 \%)$ of the theoretical values of V.C., it is evident that calculation of absolute theoretical values for R.V. and T.L.C. is practically meaningless. It is for this reason that the ratio R.V./T.L.C. should be used as the only reliable index of the R.V. in a given patient.

\section{RESULTS}

In patients with tight mitral stenosis, without clinical evidence of combined heart failure, mean values were as follows:

$$
\begin{array}{ll}
\text { Total lung capacity } & =\mathrm{ml} .5,350 \pm 1,140 \\
\text { Functional residual capacity } & =\mathrm{ml} .3,290 \pm 1,900 \\
\text { Expiratory reserve volume } & =\mathrm{ml} .1,190 \pm 450 \\
\text { Residual volume } & =\mathrm{ml} .2,090 \pm 700 \\
\text { R.V./T.L.C. } \times 100 & =38 \pm 7
\end{array}
$$

When the ratio R.V./T.L.C. $\times 100$ was studied according to the age of the patients, the following mean values were calculated:

$$
\begin{aligned}
& \text { age }<30 \text { years R.V./T.L.C. } \times 100=36 \pm 6 \\
& \text { age } 30-39 \text { years R.V./T.L.C. } \times 100=39 \pm 8 \\
& \text { age }>40 \text { years R.V./T.L.C. } \times 100=41 \pm 7
\end{aligned}
$$

The "mixing time" was in each instance equal to, or less than three minutes. This value, with our technique, is well within normal limits.

In patients of group II, in whom tight mitral stenosis and combined heart failure -were present, we observed the following mean values:

$$
\begin{array}{ll}
\text { Total lung capacity } & =\mathrm{ml} .4,460 \pm 1,280 \\
\text { Functional residual capacity } & =\mathrm{ml} .2,900 \pm 720 \\
\text { Expiratory reserve volume } & =\mathrm{ml} .1,010 \pm 280 \\
\text { Residual volume } & =\mathrm{ml} .1,890 \pm 570 \\
\text { R.V./T.L.C. } \times 100 & =42 \pm 8
\end{array}
$$

The ratio R.V./T.L.C. varied, according to the age, as follows:

$$
\begin{aligned}
& \text { age }<30 \text { years R.V./T.L.C. } \times 100=39 \pm 6 \\
& \text { age } 30-39 \text { years R.V./T.L.C. } \times 100=41 \pm 8 \\
& \text { age }>40 \text { years R.V./T.L.C. } \times 100=44 \pm 11
\end{aligned}
$$

The "mixing time" was normal.

The values observed in the two patients with predominant mitral regurgitation and no evidence of heart failure were as follows:

$$
\begin{array}{ll}
\text { Total lung capacity } & =\mathrm{ml} .4,940 \text { and c.c. } 5,440 \\
\text { Functional residual capacity } & =\mathrm{ml} .3,140 \text { and c.c. } 3,570 \\
\text { Expiratory reserve volume } & =\mathrm{ml} .1,080 \text { and c.c. } 980 \\
\text { Residual volume } & =\mathrm{ml} .2,060 \text { and c.c. } 2,600 \\
\text { R.V./T.L.C. } & =41 \text { and } 47
\end{array}
$$

In the other 8 subjects with mitral regurgitation and clinical evidence of heart failure we found the following values:

$$
\begin{array}{ll}
\text { Total lung capacity } & =\mathrm{ml} .4,110 \pm 700 \\
\text { Functional residual capacity } & =\mathrm{ml} .2,580 \pm 800 \\
\text { Expiratory reserve volume } & =\mathrm{ml} .890 \pm 280 \\
\text { Residual volume } & =\mathrm{ml} .1,700 \pm 500 \\
\text { R.V./T.L.C. } \times 100 & =41 \pm 9
\end{array}
$$

A normal "mixing time" was again found. 
It is evident from our results that residual lung volume as measured by the ratio R.V./T.L.C. is constantly increased in mitral valvular disease. These changes seemed to be greater in the patients of the older age groups.

A slightly different behaviour was observed between the patients with tight mitral stenosis without right heart failure and those with the same valvular lesion and evidence of right and left heart failure.

In both groups R.V. was increased approximately to the same extent; but T.L.C. in the decompensated group was decreased due to a diminution of the expiratory reserve volume. Therefore the ratio R.V./T.L.C. was slightly higher; this difference, however, was not statistically significant, nor was the difference between mean values of R.V. in these two groups of patients.

In patients with predominant mitral regurgitation, R.V., T.L.C., and the ratio between the two parameters showed changes similar to those observed in the previous groups.

\section{Discussion}

Our observations confirm previous reports on the expansion of the residual lung volume in mitral disease (Mathieu et al., 1953; Castaing et al., 1952; van Bogaert et al., 1955; and Englert et al., 1956).

Several explanations have been put forward to explain the changes observed. According to Mathieu (1953), the increased residual volume must be considered as a consequence of the pulmonary congestion with the superimposed broncho-pulmonary reactive fibrosis, lung hæmosiderosis, bronchial inflammation, and upper respiratory infections. All these factors would eventually lead to a loss of elasticity of the lung, and to an anatomical and functional situation comparable to early pulmonary emphysema.

Each one of the factors that we have listed above certainly contributes in some way to the pathogenesis of the increased residual volume in mitral valvular disease. However, in these conditions it never reaches the extent usually observed in pulmonary emphysema. Furthermore the normal mixing time in mitral patients indicates that in these subjects the ventilatory situation must be different from the one present in pulmonary emphysema, in which the distribution of inspired air is severely impaired and the mixing time is greatly prolonged.

Castaing et al. (1952) maintain that the increased R.V. results from a ventilatory hyperactivity, as a compensatory mechanism for the impaired hæmatosis. The functional situation of the lung in mitral patients would then be comparable to the compensatory hyperactivity of the spared lung after pneumonectomy. The pulmonary distension of the mitral lung, contrary to what is observed in emphysema, should then be considered as a favourable mechanism by which the respiratory performance is improved and only its prolonged duration could eventually lead to a permanent stiffness of the pulmonary parenchyma.

However, Marshall et al. (1954) and Christie (1953) have demonstrated that ventilatory work in patients with mitral stenosis at rest is much increased, due to the loss of the elastic properties of the lungs.

Two mechanisms may be responsible for the rigidity of the lung. The hypertensive pulmonary arterial tree can, by itself, be considered a more rigid framework for the lung (Mack, 1947). Interstitial œdema and, subsequently, the fibrotic interstitial proliferation are the obvious organic causes of lung stiffness.

Due to the loss of its elastic properties, the lung cannot return to a normal resting expiratory level; the tidal volume encroaches on the inspiratory reserve volume. It follows that the resultant rapid shallow breathing with increased residual lung volume represents an adaptation to the increased stiffness of the lung.

\section{SUMMARY}

The residual lung volume was found to be constantly increased in 60 patients with mitral valvular disease. These changes have been attributed to a loss of the elastic properties of the lung. 
In this respect the increased residual volume may represent an important link in the pathogenesis of cardiac dyspnœa.

\section{REFERENCES}

Baldwin, E. de F., Cournand, A., and Richards, D. W., Jr. (1948). Medicine, Baltimore, 27, 243.

Briscoe, W. A. (1952). Clin. Sci., 11, 45.

Castaing, R., Bricaud, H., Broustet, P., and Marty, J. (1952). Arch. Mal. Coeur, 45, 724.

Christie, R. V. (1953). Proc. Roy Soc. Med., 46, 381.

Englert, M., and Denolin, P. (1956). Acta cardiol. (Brux.), 11, 365.

Gordon, B. L. (1957). Clinical Cardiopulmonary Physiology. Grune and Stratton, New York, London.

Heyer, H. E., Holman, J., and Shires, G. T. (1948). Amer. Heart. J., 35, 463.

Mack, J., Grossman, M., and Katz, L. M. (1947). Amer. J. Physiol., 150, 654.

Marshall, R., Mcllroy, M. B., and Christie, R. V. (1954). Clin. Sci., 13, 137.

Mathieu, L., Grilliat, J. P., and Pillot, P. (1953). Arch. Mal. Caeur, 46, 341.

Pillot, P. (1954). Les Variations du Volume Pulmonaire Résiduel. Thèse de Nancy, n. 30.

Van Bogaert, A., Vandael, J., van Genabeek, A., and van der Henst, H. (1955). Arch. Mal. Caur, 48, 225.

Van Veen, G., Orie, N. G. M., and Hirdes, J. J. (1952). Acta tuberc. scand., 26, 251. 